\title{
Should Firms be Required to Pay for Vocational Training?
}

\author{
Margaret Stevens \\ margaret.stevens@economics.ox.ac.uk
}

Nuffield College and Institute of Economics and Statistics, Oxford

January 1999

\section{$\underline{\text { Abstract }}$}

Failure in the training market may result from credit constraints and the inability to insure against labour income uncertainty, deterring potential trainees, or labour market imperfections that create external benefits for firms. This paper constructs a model of a training market affected by both problems, and examines the rationale for training levy schemes, intended to make firms increase investment in vocational training. It is shown that regulating firms, or equivalently financing a subsidy through taxation of profits, can achieve a Pareto improvement irrespective of the cause of under-investment. However, when the levy is assessed as a proportion of wages the effect is to address capital market imperfections only. 


\section{Should Firms be Required to Pay for Vocational Training?}

Policy makers in several countries have attempted to increase investment in vocational training by requiring firms to bear training costs. In the UK a policy of this type operated between 1964 and 1982. For each of twenty-eight industries, an Industrial Training Board was given statutory powers to raise a training levy from the firms within the industry, then to redistribute the levy in the form of grants to those firms which were deemed to be giving an appropriate level of training to their employees. In 1971 France instituted a policy which requires employers to spend a certain percentage of payroll costs on training. The required percentage has gradually been raised since then, standing now at $1 \frac{1}{2} \%$, and the system continues to operate with little political controversy. In contrast, the very similar Australian Training Guarantee Scheme faced strong opposition from employers' organisations and was suspended in 1994, after only four years ${ }^{1}$.

The supposed economic rationale for such intervention is that training creates external benefits for other firms. A firm will be deterred from investing sufficiently in training because trained workers might leave, and the firm would then be unable to capture the benefits. A mechanism is needed to ensure that firms cannot free-ride by "poaching" skilled labour from other firms. But this argument has found little favour with economists in recent years, and few have defended the use of levy schemes.

Perfectly competitive markets ensure optimal investment in training as follows. Provided that the skills are "general" (Becker, 1962) they can be traded in a competitive

\footnotetext{
${ }^{1}$ See Finegold and Crouch (1994) for discussion of the schemes in these and other countries.
} 
labour market: a generally-trained worker is paid his marginal product, and thus receives the full return from the training investment. Moreover, he is fully informed about the expected return, and can borrow at a competitive interest rate in order to finance the investment. The decision as to whether to undertake training is his alone; even if training takes place "on-the-job" the firm is involved only passively, as the supplier of the training which the worker demands, and the worker pays by accepting lower wages during the training period. The firm will not invest in training, since it cannot obtain a return. But optimal investment follows from the decisions of rational workers.

There are two principal theoretical explanations for failure in the market for vocational training. One is that potential trainees do not invest in training because they face capital market problems: they cannot borrow against human capital, or insure themselves against associated risks. The second is that the skilled labour market is not perfectly competitive, so that the wage is not equal to the marginal product of the worker. In this case, both the worker and the firm where he trains may obtain part of the expected return to an investment in training, in which case they will share the costs. However, if it is possible that the worker will move to an alternative firm that will pay him a wage below marginal product, this constitutes an external benefit which will lead to under-investment.

Thus, market failure arguments seem to suggest that a policy which imposes additional training costs on firms can be justified if the cause of under-investment is an imperfectly competitive labour market, but is inappropriate if the main problem originates in the capital market. In this paper I investigate this proposition, and explore the role of levy schemes in training policy. 
I construct a model of the market for vocational training which allows for both labour and capital market imperfections. The model allows us to examine how these two sources of under-investment interact, and to assess the effects of policy. If the only source of under-investment is labour market imperfections, a policy of requiring firms to increase training expenditure beyond their private choice can achieve the first-best training outcome. In addition, it is an effective second-best response to capital market imperfections, in the sense that it can raise the welfare of both firms and workers. On the other hand, a subsidy financed through wage taxation can address capital market problems but cannot alleviate under-investment due to labour market imperfections. These results suggest two conclusions about training levy schemes: first, there is an economic rationale for imposing training costs on firms, whether the main source of under-investment is in the labour or the capital market; but second, if in practice the firm's liability is assessed as a proportion of wages, the effect is to address capital market problems only.

\section{Explanations for Training Market Failure ${ }^{2}$}

\subsection{Labour and Capital Market Imperfections}

The theoretical economic analysis of vocational training usually begins with Becker's (1962) distinction between general training, which produces human capital that is productive in many firms, and specific training, which produces skills that are only useful

\footnotetext{
${ }^{2}$ A brief overview is given here; see Stevens (1999) for a fuller discussion and Booth and Snower (1996) for extensive analyses.
} 
in a single firm ${ }^{3}$. Becker demonstrated that there are no external benefits to general training, and concluded that under-investment in general skills must be due to the credit constraints facing trainees. Following Becker's lead, Lees and Chiplin (1970) argued that, since he had exposed the poaching argument as a fallacy, there was no economic justification for the UK training levy. Instead they recommended that the focus of policy should be the capital market problems affecting potential trainees. Similarly, Layard, Robinson and Steedman (1995) see "no clear reason why firms should be made to pay".

There seems to be general acceptance of the view that, since human capital cannot be used as security for a loan, credit constraints are an important obstacle to training. The source of the problem can be traced to the asymmetries of information and associated moral hazard problems which make it infeasible to write complete loan contracts. Acemoglu (1996) presents a simple demonstration of the reduction in skill acquisition and growth when trainees cannot obtain loans and hence cannot invest more than their initial endowment.

A related problem is the uncertainty in the return to a training investment. This may arise, for example, because of shocks to the demand for particular skills, or because of the worker's uncertainty about his ability to obtain a qualification. Layard, Robinson and Steedman (1995) emphasise that uncertainty is a significant deterrent to investment by risk-averse workers. Workers are unlikely to be able to obtain insurance against these types of risks, since again there are obvious moral hazard problems. Hamilton (1987)

\footnotetext{
${ }^{3}$ Specific skills will not be considered in this paper; while there are reasons to suppose that investment in specific training may be sub-optimal (for example, there may be a "hold-up" problem) there are fewer compelling arguments for public intervention.
} 
analyses optimal tax policy when individuals invest too little in human capital as a result of uncertainty. In his model, an optimal wage tax can reduce under-investment, but does not eliminate it because of the incentive problems.

Becker's analysis relies on the presumption that the labour market for generally skilled workers must necessarily be perfectly competitive. Stevens $(1994,1996)$ and Acemoglu (1996) both argue that an imperfectly competitive labour market may cause under-investment in training. Stevens suggests a distinction between general skills and transferable skills - skills which are of value in more than one firm (so must be analysed differently from specific skills) but differ from general skills in that they are traded in a labour market which is not perfectly competitive, so that the skilled worker is paid a wage less than his marginal product. Imperfect competition may arise because the skills are useful only in a small number of firms, or because firms are differentiated in their skill requirements, or because of matching frictions. Then, training may raise productivity more than it raises the wage, in which case the expected return to the training investment is shared between the worker and any firms in which the skills may be employed after training. If training takes place during employment, the employer may share the costs of the investment with the worker, but an externality arises because alternative employers obtain part of the expected benefit but do not share the costs. In the model of Stevens (1994), the resultant effect is under-investment in transferable skills, and also overinvestment in specific skills, since these reduce mobility and hence the expected benefit to external firms.

This argument provides some theoretical justification for policies requiring firms to pay for training. But it is difficult to assess its practical significance. We know that labour 
markets are affected by frictions, that workers are not always perfectly mobile, and firms are differentiated in their skill requirements because they use adopt different technologies. All these factors may give monopsony power to firms, but we do not know their quantitative effects. We can say, however, that some features of labour markets are difficult to explain without acknowledging the existence of imperfect competition between firms. Acemoglu (1996) argues that evidence of skill shortages is strongly suggestive of imperfect competition in the labour market. Card and Krueger (1995) interpret their evidence on minimum wages similarly. In particular, evidence that firms do appear to incur net costs in the provision of "general" training (Bishop, 1991; Jones, 1986) is hard to reconcile with perfect competition.

Surveys of employers' attitudes to training and poaching are difficult to interpret. A finding that employers are deterred from providing training because they may lose the trained workers to other firms is entirely consistent with a competitive labour market - it does not necessarily constitute evidence of a poaching externality. On the other hand a recent survey by the Confederation of British Industry (1997) found that employers believe themselves to provide training which is highly transferable, but nevertheless that it increases the likelihood of retaining employees by instilling "greater organisational commitment". Although the CBI interpreted this as evidence against poaching, it does suggest that training increases the labour market power of employers, and it is precisely in these circumstances that there may be under-investment due to a poaching externality. 


\subsection{Other Explanations}

Several authors have examined the effects of asymmetric information about the training offered by a particular firm, or the skills possessed by an individual worker. If potential employers are less well-informed about a worker's skills than the firm where he trained, the effect is to reduce competition in the labour market. In the model of Acemoglu and Pischke (1998) training firms acquire superior knowledge about the ability of trainees. The information advantage causes adverse selection and hence monopsony power for the training firm. General training, and the worker's ability (about which the firm has superior knowledge, which is, effectively, a specific asset) are complements. This means that firms can obtain part of the return to the general training, as well as the specific element, and will therefore be willing to incur training costs. In addition, there is underinvestment: in equilibrium, there is less training than there would be at the full-information first-best outcome, because of the effect of adverse selection. However, in this model there is no externality: alternative employers do not have labour market power.

Asymmetric information between the training firm and trainee may lead to market failure in the training market itself, rather than indirectly through the labour market. A problem of moral hazard arises if the trainee is unable to monitor the quality of the training provided by his employer. Malcolmson, Maw and McCormick (1997) show that this can lead to under-provision, and recommend regulation of both standards of training and the length of training contracts.

The implications of these analyses of asymmetric information for the policy-maker are somewhat mixed. It may be possible to mitigate information problems by instituting and supporting a system of vocational qualifications (as the UK government attempted to 
do with the establishment in 1986 of the National Council for Vocational Qualifications). But as both Acemoglu and Pischke (1998) and Katz and Ziderman (1990) have pointed out, asymmetric information may be beneficial when trainees are unable to invest in training because of credit constraints. By diverting part of the return to training from the worker to the firm, it gives firms an incentive to invest. In Acemoglu and Pischke's model, credit constraints are assumed to imply that trainees will not bear any training costs. With such rigid credit constraints, no training takes place under full information, so the outcome under asymmetric information, in which firms invest, is necessarily superior.

The policy maker should, therefore, be aware that improved certification may have a negative effect in the presence of credit constraints. However, in the absence of certification to provide an objective measure of training activity, it would be difficult to implement any policy measures to increase training. For this reason, I assume in the model developed below that skills are certificated, and the information problems outlined above do not arise.

Finally, there is one more potential explanation for under-investment in skills which may be particularly important in conditions of technological change, but which I do not allow for in the present paper. This is a co-ordination problem between workers, as investors in human capital, and firms, as investors in new technology, because the two investments are complementary. Workers' returns to investment in skills depend upon firms investing in the technology which will require those skills, and firms' returns to investment in that technology depend upon the existence of a supply of skilled labour to operate it. Redding (1996) presents a growth model to illustrate this problem, showing that under certain conditions it can lead to multiple equilibria. The models of Snower 
(1996) and Acemoglu (1996) work in a similar way. All these models have an imperfectly competitive labour market, and also require the assumption that firms and workers must make their investment decisions before entering the labour market so are not able to contract on their investments.

\section{The Model}

Consider a particular skill, which is of potential value in a large number of firms. Workers are initially unskilled and are not attached to firms. In the first period, the firms offer traineeships, consisting of a guarantee that the training will be provided (either on- or off-the-job) and a training wage for the period.

Workers accept offers which maximise their expected utility. They are risk-averse, and can choose to borrow to smooth their income, although they may be creditconstrained. To evaluate the offers of training they must form expectations about the wages that will be available to them when the firms compete for skilled workers in the second period. The skilled labour market is not perfectly competitive: it is envisaged as a search market, in which firms have power to set wages. This market power will tend to lower expected wages, but will mean that firms, as well as workers, can expect a return from training.

Although the training is of a standard type, and the average productivity of skilled workers is known, each worker's trainability is initially unknown - some will acquire greater skill than others. Once training is complete, the worker's level of skill is observable and he will be paid accordingly. Thus, workers face uncertainty which may deter them from investing in training. 
The number of workers trained in equilibrium will depend on the degree of uncertainty about future skill level, the severity of credit constraints, and the degree of market power possessed by firms in the skilled labour market. It will also be affected by the way expectations are formed.

\subsection{Basic Ingredients}

There are many firms, indexed by $i$ and ordered according to their fixed cost of entry to the market for a particular type of skilled labour, but otherwise identical. The entry cost for firm $i$ is $E(i)$, where $E^{\prime}(i)>0$.There are two periods: training occurs in the first period, and employment in the second. In the first period firm $i$ chooses whether to enter, and if so, how many workers to train. If it trains $T_{i}$ workers the cost of training is $C\left(T_{i}\right): C^{\prime}>0, C^{\prime \prime}>0$.

There is no discounting between periods. Firms are risk-neutral and maximise profit; they can borrow and save at a zero interest rate. Workers are risk-averse and maximise expected utility; they may face credit constraints represented by an interest rate $r \geq 0$ on loans.

There are many workers who must decide whether to undertake training. They have per-period utility of income $u(W)$, where $u$ is a "constant absolute risk aversion" utility function:

$$
u(W)=\frac{-1}{\alpha} e^{-\alpha W} \quad \alpha>0
$$

Workers are ordered according to their reservation wage: the $j$ th worker can receive a wage $W_{0}(j)$ in each period if he chooses not to train, where $W_{0}^{\prime}(j) \geq 0$. 
There is some uncertainty about how efficient an individual skilled worker will be. His efficiency is revealed at the end of training, and is then common knowledge. With probability $1 / 2$ he will be a more efficient worker, worth $(1+\delta)$ efficiency units, otherwise he will be less efficient, worth $(1-\delta)$ efficiency units $(\delta<1)$.

In the second period firm $i$ employs $N_{i, 1+\delta}$ efficient skilled workers, and $N_{i, 1-\delta}$ less efficient skilled workers. Hence the skilled labour input is:

$$
N_{i}=(1+\delta) N_{i, 1+\delta}+(1-\delta) N_{i, 1-\delta}
$$

The production function is $f\left(N_{i}\right) ; f^{\prime}>0, f^{\prime \prime}<0$.

\subsection{The Skilled Labour Market}

Suppose that all firms with $0 \leq i \leq m$ (where $m$ is large) have entered the market. The labour market is subject to frictions, which give firms some market power. At the start of the second period firm $i$ sets wages $W_{i, e}$ for workers of efficiency $e$ where $e=1+\delta, 1-\delta$. Frictions arise from the slow arrival of information for workers about alternative job opportunities. So, if a worker enters the labour market after training, he must search for a job. Rather than modelling the search process explicitly, we suppose that the outcome is to allocate a worker trained in firm $i$ to firm $j$ with probability $p_{i j}$, which is increasing in the wage $W_{j, e}$ available in that firm: 


$$
\begin{aligned}
& p_{i i e}=\left(\mu+\frac{1-\mu}{m}\right)\left(\frac{W_{i, e}}{\bar{W}_{i, e}}\right)^{\eta} \\
& p_{i j e}=\frac{1-\mu}{m}\left(\frac{W_{j, e}}{\bar{W}_{i, e}}\right)^{\eta} j \neq i \\
& \text { where } \eta \geq 1 \text { and } \bar{W}_{i, e}=\left(\mu W_{i, e}^{\eta}+\frac{1-\mu}{m} \sum_{j=1}^{m} W_{j, e}^{\eta}\right)^{\frac{1}{\eta}}
\end{aligned}
$$

Since the worker is initially attached to the training firm, the search process is weighted in favour of that firm: he is already aware of the jobs available in the training firm, but has to search for alternatives. So he has positive probability of remaining in firm $i$, but the probability of working in another firm, $j$, is negligible (of order $1 / m$ ). This inertia is represented by the parameter $\mu \in(0,1)$.

The parameter $\eta$ represents market power in a familiar way: as $\eta$ approaches infinity, the worker is allocated with probability 1 to the firm offering the highest wage: the market is perfectly competitive.

$\bar{W}_{i, e}$ is a wage index for workers trained in firm $i$, chosen so that the probabilities sum to one. Note that, since $m$ is large, the wage set in firm $j$ has a negligible effect on the wage index for workers trained in firm $i \neq j$ (for finite $\eta$ ), whereas, since $\mu>0$, the effect of firm $i$ 's wage on its own wage index is non-negligible.

\subsubsection{Labour Market Equilibrium}

Given that the firms have trained $\left\{T_{j}\right\}_{j=1, ., \mathrm{m}}$ workers, the second period expected labour supply of workers of efficiency $e$ to firm $i$ is:

$$
N_{i, e}=\frac{1}{2} W_{i, e}^{\eta}\left(\mu \frac{T_{i}}{\overline{W_{i, e}^{\eta}}}+\frac{1-\mu}{m} \sum_{j=1}^{m} \frac{T_{j}}{\bar{W}_{j, e}^{\eta}}\right)
$$


and total labour supply is $N_{i}$ given by (1). We will suppose that the number of workers is sufficiently large that the firm can ignore random variation in the proportion of efficient workers, and treat labour supply as deterministic.

Firm $i$ chooses wages $W_{i, e}, e=1+\delta, 1-\delta$, to maximise

$$
\Pi_{i}=f\left(N_{i}\right)-W_{i, 1+\delta} N_{i, 1+\delta}-W_{i, 1-\delta} N_{i, 1-\delta}
$$

taking all other firms' choices as given. The first order conditions are:

$$
\left(e f^{\prime}\left(N_{i}\right)-W_{i, e}\right) \frac{\partial N_{i, e}}{\partial W_{i, e}}=N_{i, e} \quad \text { for } i=1, \ldots, m ; e=1+\delta, 1-\delta
$$

It is clear that one solution is for each firm to choose an average skilled wage $W_{i}$ and then set $W_{i, e}=e W_{i}$. We focus on this solution ${ }^{4}$. Then labour market equilibrium is described by the following equations:

$$
\begin{aligned}
& W_{i, e}=e W_{i} ; \quad N_{i, e}=\frac{1}{2} N_{i} \\
& N_{i}=W_{i}^{\eta}\left(\mu \frac{T_{i}}{\bar{W}_{i}^{\eta}}+\frac{1-\mu}{m} \sum_{j=1}^{m} \frac{T_{j}}{\bar{W}_{j}^{\eta}}\right) \\
& \left(f^{\prime}\left(N_{i}\right)-W_{i}\right) \frac{\partial N_{i}}{\partial W_{i}}=N_{i} \quad \text { for } i=1, \ldots, m
\end{aligned}
$$

\subsubsection{A Symmetric Labour Market Equilibrium}

If it happens that all firms choose the same level of training, $T_{i}=T$, in the first period, then in a symmetric Nash equilibrium in the second period all firms employ $T$

\footnotetext{
${ }^{4}$ Since all firms are identical we will eventually arrive at a symmetric equilibrium, which has this property. Nothing is lost if we assume from now on that this holds, and there is a considerable gain in notational simplicity.
} 
skilled workers and set the same wage $W_{i}=W$. From equations (6) we obtain (ignoring terms of order $1 / m)$ :

$$
f^{\prime}(T)=W\left(1+\frac{1}{\eta^{\prime}}\right) \text { where } \eta^{\prime}=\eta\left(1-\mu^{2}\right)
$$

The parameter $\eta^{\prime}$ represents the firm's power to set wages. As $\eta \rightarrow \infty$, the wage approaches the marginal product of labour. When $\eta$ is finite, wage-setting power is enhanced by the inertia of trainees.

\subsubsection{The Firm's Private Benefit from Training}

We can see from the equilibrium conditions (6) that firm $i$ 's own training affects its second period labour supply directly, and also affects the equilibrium wage in firm $i$. However, since $m$ is large, the training of any other individual firm has a negligible effect on labour supply and equilibrium wages in firm $i$.

By differentiating the first order conditions with respect to $T_{i}$ we can derive the effect of firm $i$ 's training on its own wage. It is shown in the appendix that at the symmetric equilibrium:

$$
\frac{T}{W} \frac{\partial W_{i}}{\partial T_{i}}=-\frac{\mu}{\eta^{\prime}} k \quad \text { where } k \in(0,1)
$$

$k$ depends on $\mu$ and $\eta^{\prime}$, and on the elasticity of labour demand $\left(|\varepsilon|=-f^{\prime} / T f^{\prime \prime}\right)$.

Now consider the effect of the firm's own training, $T_{i}$, on its second period profit when wages are optimally chosen, $\Pi_{i} *\left(T_{i}\right)$. By the envelope theorem the effect acting through wages disappears, so we obtain:

$$
\frac{d \Pi_{i}^{*}}{d T_{i}}=\left(f^{\prime}\left(N_{i}\right)-W_{i}\right) \frac{\partial N_{i}}{\partial T_{i}}
$$


Evaluating this at the symmetric equilibrium gives:

$$
\frac{d \Pi_{i}^{*}}{d T_{i}}=\frac{W \mu}{\eta^{\prime}}=\frac{\mu f^{\prime}(T)}{1+\eta^{\prime}}
$$

The benefit to the firm of training the marginal worker is the difference between the wage and the marginal product, multiplied by the probability that the firm will retain the worker.

\subsection{The Demand for Training}

Consider a worker with reservation wage $W_{0}$, who must decide whether to train. We will assume that the reservation wage is equal to the worker's productivity without training. If he does not train, he obtains two-period utility $2 u\left(W_{0}\right)$. If he chooses to train in firm $i$, he will be paid a training wage $\left(W_{0}-P_{i}\right)$, where $P_{i}$ is the price of training in firm $i$. Suppose that he anticipates that the wages for skilled workers will be:

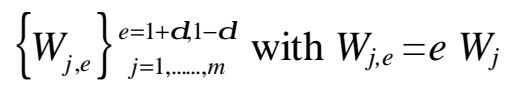

His expected second-period utility if he trains in firm $i$ is $u\left(W_{i}^{c}\right)$ where $W_{i}^{c}$ is the certainty equivalent of the wages available in the second period, taking into account the probability of working in each firm:

$$
\begin{gathered}
\exp \left(-\alpha W_{i}^{c}\right) \equiv \frac{1}{2} \sum_{e}\left(p_{i i e} \exp \left(-\alpha W_{i, e}\right)+\sum_{j \neq i} p_{i j e} \exp \left(-\alpha W_{j, e}\right)\right) \\
=\left(\mu+\frac{1-\mu}{m}\right)\left(\frac{W_{i}}{\overline{W_{i}}}\right)^{\eta} \exp \left(-\alpha W_{i}\right) h\left(\alpha \delta W_{i}\right)+\frac{1-\mu}{m} \sum_{j \neq i}\left(\frac{W_{j}}{\overline{W_{i}}}\right)^{\eta} \exp \left(-\alpha W_{j}\right) h\left(\alpha \delta W_{j}\right) \\
\text { where } h(x) \equiv \frac{1}{2}\left(e^{-x}+e^{x}\right)
\end{gathered}
$$

$h\left(\alpha \delta W_{i}\right)$ is the discount factor that a worker applies to utility from the average wage in firm $i$ because of the uncertainty in his efficiency. Suppose the worker decides to train in 
firm $i$ and takes out a loan $L$ in the first period, to be repaid in the second. Then his twoperiod utility gain is given by:

$$
U=u\left(W_{i}^{c}\right) \exp (\alpha(1+r) L)+u\left(W_{0}-P_{i}\right) \exp (-\alpha L)-2 u\left(W_{0}\right)
$$

The optimal loan maximises $U$, and hence satisfies:

$$
L=0 \text { if } \alpha\left(W_{i}^{c}-W_{0}+P\right)<\ln (1+r)
$$

otherwise: $(1+r) u\left(W_{i}^{c}\right) \exp (\alpha(1+r) L)=u\left(W_{0}-P_{i}\right) \exp (-\alpha L)$

Training in firm $i$ is preferable to remaining untrained if $U^{*} \geq 0$ where $U^{*}$ is the two period utility gain from training with an optimal loan. Solving for $U^{*}$ from (12) and (13) leads, after a little manipulation, to the following condition:

The utility gain from training in firm $i$ is positive for worker $j$ if and only if:

$$
W_{c}^{i}-W_{0}(j) \geq \phi\left(P_{i}, r\right)
$$

where

$$
\begin{aligned}
\phi(P, r) & \equiv P(1+r)-\frac{(1+r)}{\alpha} \ln (1+r)+\frac{(2+r)}{\alpha} \ln \left(1+\frac{1}{2} r\right) \text { if } \alpha P>\ln \left(\frac{1+r}{1+\frac{1}{2} r}\right) \\
& \equiv-\frac{1}{\alpha} \ln \left(2-e^{\alpha P}\right) \text { otherwise }
\end{aligned}
$$

With a perfect capital market this condition reduces to $W_{c}^{i}-W_{0}(j) \geq P_{i}$ : the gain in wages is greater than the price. It can be verified that $\phi \geq 0, \phi_{r} \geq 0$ and $\phi_{P} \geq 1$. Hence, as the interest rate rises, the wage gain required at a given price also rises. As the interest rate approaches infinity, the possibility of a loan is ruled out, and no worker will undertake training unless the price is below $\ln (2) / \alpha$. 
In some of what follows, we will simplify the algebra by restricting attention to the case when credit constraints are moderate and the price of training is not too low - that is, when the condition $\alpha P>\ln \left(\frac{1+r}{1+\frac{1}{2} r}\right)$ holds. This is sufficient to ensure that any worker who chooses to undertake training will do so with a loan. It can then be verified that the utility gain from training is given by:

$$
U^{*}=\frac{2}{\alpha} \exp \left(-\alpha W_{0}(j)\right)\left(1-\exp \left(-\frac{\alpha}{2+r}\left(W_{i}^{c}-W_{0}(j)-\phi\left(P_{i}, r\right)\right)\right)\right)
$$

\subsection{The Training Market}

We will simplify the analysis of the training market as much as possible, by assuming that there are no frictions: workers are fully aware of all the available training opportunities, and will choose to train in the firm where the gain from training is highest. This may seem implausible if accompanied by the assumption that the skilled labour market is not frictionless; however, the effect of frictions in the training market is not of great interest - they will simply reduce the equilibrium quantity of training in the obvious way. By ignoring them we obtain a clearer picture of the more complex effects of capital and skilled labour market imperfections.

Thus the training market will be modelled as competitive. Usually in a competitive market consumers prefer the lowest price and so firms are price-takers; here workers prefer the firm where the utility gain from training is highest, and the gain in utility depends not only on the price $P_{i}$, but also on the expected certainty-equivalent wage $W_{i}^{c}$. 
If trainees have rational expectations $W_{i}^{c}$ depends on the number of workers trained in firm $i$.

The rational expectations case will be examined in section 2.6. For now, we will simplify further by assuming that potential trainees form expectations more crudely: they understand that the more workers are trained, the lower will be skilled wages, but they are not fully rational, in that they expect skilled employment and wages to be the same in every firm. Specifically, if $m$ firms enter the market and $n$ workers are trained, all workers believe that the wage for workers of efficiency $e$ will be $W_{e}=e W$, where:

$$
f^{\prime}(n / m)=W\left(1+\frac{1}{\eta^{\prime}}\right)
$$

with (using (11)) corresponding certainty equivalent:

$$
W^{c}=W-\frac{\ln (h(\alpha \delta W))}{\alpha}
$$

They do not recognise that a firm training fewer workers than other firms can be expected to offer a higher skilled wage. However, since in equilibrium all firms will train the same number of workers, their expectation will be fulfilled. With this assumption, the relative utility gain in different firms depends only on the price, and so firms and workers are price-takers.

\subsubsection{The Training Supply Function}

Given a price $P$ for training, the firm chooses its training $T_{i}$ to maximise $\Pi^{*}\left(T_{i}\right)+\mathrm{P} T_{i}-C\left(T_{i}\right)$. When all firms choose the same number of trainees, the firm's private benefit from training is given by equation (10), and so the training supply function is: 


$$
\frac{\mu f^{\prime}(T)}{1+\eta^{\prime}}+P-C^{\prime}(T)=0
$$

(where $T$ is the number of trainees per firm, and $m T$ is aggregate training supply). The firm chooses training such that price equals marginal cost, unless the labour market is imperfectly competitive. Even then, with a wage below the marginal product of labour, it is prepared to pay for training only because it has a higher probability of employing its own trainee than a random worker from the external labour market $(\mu>0)$. Increases in frictions $\left(\mu\right.$ or $\left.1 / \eta^{\prime}\right)$ shift the training supply function to the right and increase its slope (see Figure 1). Uncertainty $(\delta>0)$ and credit constraints $(r>0)$ have no effect on training supply.

\subsubsection{The Training Demand Function}

If $n$ workers demand training at a market price $P$, the expected utility gain of the $n$th worker is zero. Writing $T \equiv n / m$ we can use (14), (17) and (18) to express the training demand function in terms of the number of workers per firm:

$$
W-\frac{\ln (h(\alpha \delta W))}{\alpha}-W_{0}(m T)=\phi(P, r) \quad \text { where } f^{\prime}(T)=W\left(1+\frac{1}{\eta^{\prime}}\right)
$$

It can be easily verified that the slope of the demand function is negative and that increasing uncertainty $(\delta)$ or credit constraints $(r)$ shift the function to the left and flatten it. Labour market frictions $\left(1 / \eta^{\prime}\right)$ also shift it to the left. The effect of frictions on the slope is ambiguous, but unless the wage is high and very uncertain they also tend to flatten demand. (See Figure 1). 


\subsection{Training Market Equilibrium}

The supply and demand functions (19) and (20), together with an entry condition for firms, determine the equilibrium number of trainees per firm, $T^{*}(\delta, r, 1 / \eta, \mu)$, the number of firms $m^{*}(\delta, r, 1 / \eta, \mu)$, the price of training and the skilled wage.

$$
\begin{aligned}
& \frac{\mu f^{\prime}(T)}{1+\eta^{\prime}}+P-C^{\prime}(T)=0 \\
& f^{\prime}(T)=W\left(1+\frac{1}{\eta^{\prime}}\right) \\
& W-\frac{\ln (h(\alpha \delta W))}{\alpha}-W_{0}(m T)=\phi(P, r) \\
& f(T)-W T+P T-C(T)=E(m)
\end{aligned}
$$

In the analysis of the equilibrium we will restrict attention to the case of moderate credit constraints (see section 2.3). This ensures that all workers who undertake training will do so with a loan. As a result, the form of the demand function is simplified (the function $\phi$ is given by the top line in equation (15) only), and we also obtain a simpler expression for worker welfare.

\subsubsection{Equilibrium Welfare}

The welfare of firms at the market equilibrium can be represented by producer surplus, which is:

$$
\Psi_{f} \equiv \sum_{i=1}^{m^{*}}\left(E\left(m^{*}\right)-E(i)\right)
$$

The welfare of workers can be represented by the sum of their utility gains. Assuming moderate credit constraints this can be written (using (16)): 


$$
\Psi_{w} \equiv \frac{2}{\alpha} \sum_{j=1}^{m^{*} T^{*}} \exp \left(-\alpha W_{0}(j)\right)\left(1-\exp \left(-\frac{\alpha}{2+r}\left(W_{0}\left(m^{*} T^{*}\right)-W_{0}(j)\right)\right)\right)
$$

Hence firm welfare is an increasing function of the number of firms $m^{*}$ in the market, and worker welfare is an increasing function of total training $m * T^{*}$.

\subsubsection{First-Best Outcome}

If there is perfect competition in the labour market and credit market, so that workers are paid their marginal product and can obtain loans at the competitive (zero) interest rate, and if they can also obtain full insurance, we have the first-best training outcome $(\delta=r=1 / \eta=0$ in equations $(21))$ :

$$
\begin{aligned}
& f^{\prime}\left(T_{f}\right)-C^{\prime}\left(T_{f}\right)=W_{0}\left(m_{f} T_{f}\right) \\
& f\left(T_{f}\right)-C\left(T_{f}\right)=T W_{0}\left(m_{f} T_{f}\right)+E\left(m_{f}\right) \\
& P=C^{\prime}\left(T_{f}\right) ; W=f^{\prime}\left(T_{f}\right)
\end{aligned}
$$

Workers pay the full marginal cost of training, and reap the full return in the form of enhanced wages.

\subsubsection{Comparative Statics: Capital Market Imperfections}

Differentiating (21) with respect to $r$ and $\delta$ gives (see appendix for calculations):

$$
\frac{\partial T^{*}}{\partial r}<0 ; \frac{\partial m^{*}}{\partial r}<0 ; \frac{\partial T^{*}}{\partial \delta}<0 ; \frac{\partial m^{*}}{\partial \delta}<0
$$

Thus, an increase in credit constraints or uncertainty always lowers both the number of firms and the amount of training per firm. From (22) and (23) it follows immediately that welfare of both firms and workers is reduced. 
The intuition for these results is clear: when loans are more expensive or the outcome of training is more uncertain the demand for training falls. There is no change in the supply function of an individual firm, so the amount of training per firm falls, and firm profits fall prompting some firms to leave the market.

\subsubsection{Comparative Statics: Labour Market Imperfections}

In general the effect on equilibrium training of an increase in labour market friction $(1 / \eta)$ is ambiguous. Frictions lead to a fall in the demand for training, because expected wages are lower, but they also cause an increase in supply. Differentiating (21) with respect to $1 / \eta$ (again, calculations are given in the appendix) leads to the following results:

(a) When $r$ and $\delta$ are small (and in particular if $r=\delta=0) \frac{\partial T^{*}}{\partial(1 / \eta)}<0$ and $\frac{\partial\left(m^{*} T^{*}\right)}{\partial(1 / \eta)}<0$. The sign of $\frac{\partial m^{*}}{\partial(1 / \eta)}$ is ambiguous.

So, with a near-perfect capital market, labour market frictions always decrease training. They decrease demand and increase supply, but the decrease in demand always dominates the increase in supply. The intuition for this result is quite simple: labour market frictions reduce the wage, raising the return to training for firms and lowering it for workers. But a worker loses whether or not he changes firm after training, whereas his training firm only gains if the worker stays, which he does with probability less than one. However, the overall effect on firm welfare is ambiguous; although they lose from the decline in the supply of skilled workers, they also gain directly from the reduction in the wage.

(b) When $r$ or $\delta$ is sufficiently high, $\frac{\partial\left(m^{*} T^{*}\right)}{\partial(1 / \eta)}>0$ and $\frac{\partial\left(m^{*}\right)}{\partial(1 / \eta)}>0$. 
This means that labour market imperfections can be beneficial for both workers and firms, because they can mitigate the effects of capital market problems. When demand for training is already low because of uncertainty or credit constraints, an increase in friction and consequent reduction in the wage has little effect on demand. Then the increase in supply outweighs the fall in demand, and the overall effect on training is positive.

Note that, from (a) and the results in 2.5 .3 , we can deduce that the total quantity of training $m^{*} T^{*}$ and the number of trainees per firm, $T^{*}$, are always lower than first-best in the presence of any of the three types of market imperfection. Figure 1 illustrates this result.

Consider finally the effect of an increase in inertia, $\mu$. When there are no labour market frictions $(1 / \eta=0)$, this has no effect. In the presence of frictions, an increase in $\mu$ has a similar effect to an increase in $1 / \eta$, in that it enhances wage-setting power. In addition, it directly increases the incentive for the firm to provide training. The sign of the composite effect is ambiguous; however we can say that if increases in $1 / \eta$ have a positive effect on total training, then increases in $\mu$ will also have a positive effect.

The results in this section illustrate the discussion of the problem of "poaching" in section 1.1 above. It is when there are labour market frictions that employers have an incentive to pay for training - the supply of training increases. From the point of view of the employer, when frictions are high poaching is perceived to be less of a problem. But, if there are no capital market problems, the increase in supply is always outweighed by a fall in demand, so the overall effect of frictions is to reduce equilibrium training. The joint return to training for the firm and the trainee falls, because some of the benefit 


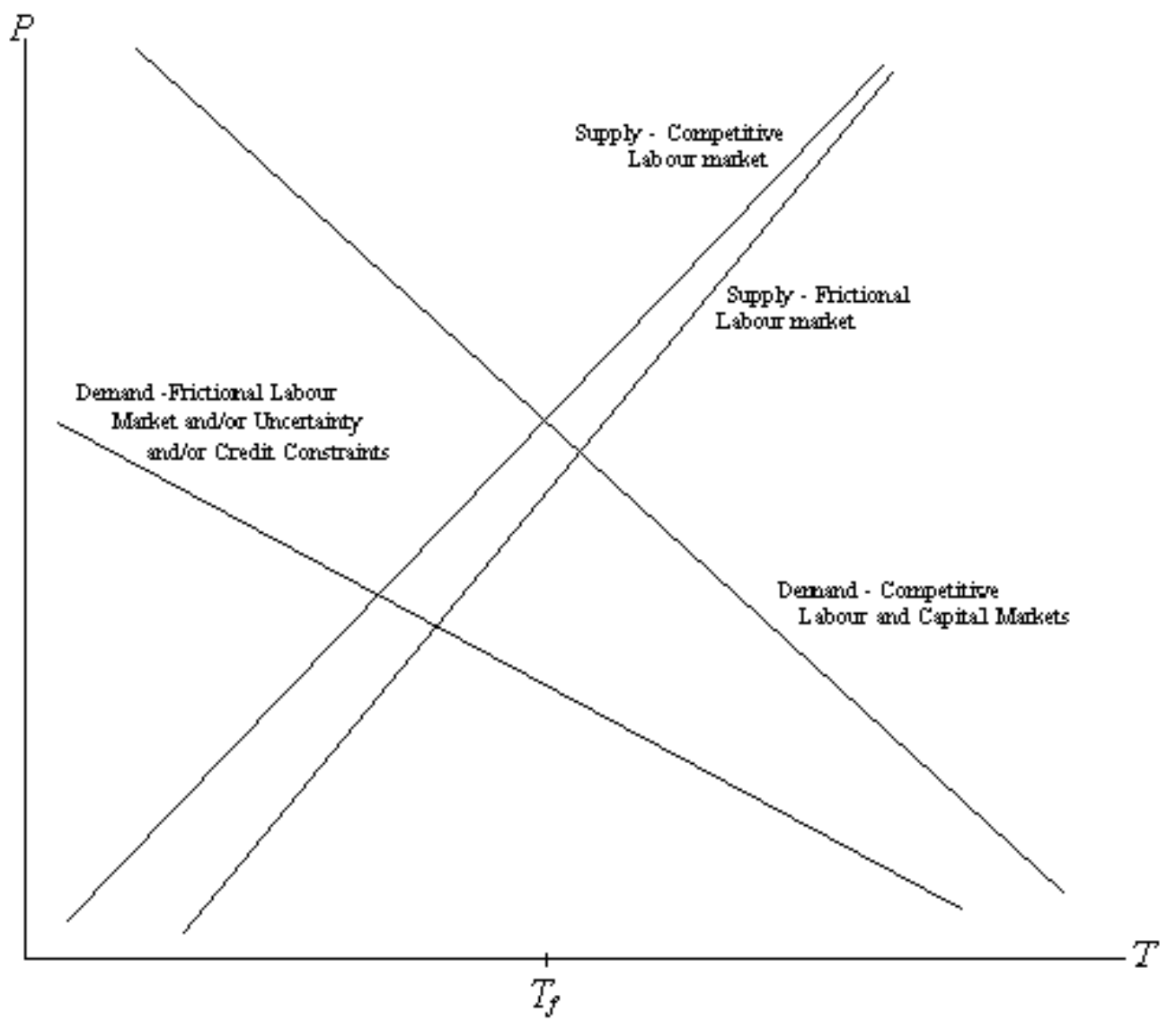

FIGURE 1: Effect of capital and labour market imperfections on equilibrium training.

accrues to external firms. On the other hand, when demand is already low due to capital market imperfections, the net effect of labour market frictions can be positive. There is still a poaching externality - investment in training is lower than it would be if the benefits to other firms were taken into account - but there is more training than would occur in the absence of frictions. 


\subsection{Modification for fully rational expectations}

When workers have rational expectations, they prefer to train in the firm where the utility gain from training is highest. Again focusing on the case of moderate credit constraints, it can be seen from (16) that this is equivalent to choosing the firm where $X_{i} \equiv W_{i}^{c}-(1+r) P_{i}$ is greatest. So we can model the competitive firm as choosing the price and quantity of training subject to the constraint that the combined effect of these decisions is to provide the market level of training-utility-gain. Thus, it chooses $\mathrm{P}_{i}$ and $T_{i}$ to maximise:

$$
\Pi^{*}\left(T_{i}\right)+\mathrm{P}_{i} T_{i}-C\left(T_{i}\right) \text { subject to } W_{i}^{c}-(1+r) P_{i}=X
$$

where $X$ is the market level of utility gain. The first-order condition is:

$$
\frac{\partial \Pi^{*}}{\partial T_{i}}+P_{i}-C^{\prime}\left(T_{i}\right)+\frac{T_{i}}{1+r} \frac{\partial W_{i}^{c}}{\partial T_{i}}=0
$$

In equilibrium each firm sets the same price and quantity of training, and we can show (using (8)) that:

$$
\frac{\partial W_{i}^{c}}{\partial T_{i}}=\mu\left(1-\frac{\delta h^{\prime}(\alpha \delta W)}{h(\alpha \delta W)}\right) \frac{\partial W_{i}}{\partial T_{i}}=\frac{-\mu^{2} k}{\eta^{\prime}}\left(1-\frac{\delta h^{\prime}(\alpha \delta W)}{h(\alpha \delta W)}\right) \frac{W}{T}
$$

So equilibrium is determined by the same equations (21) except that the first equation is modified to include an additional negative term:

$$
\frac{\mu f^{\prime}(T)}{1+\eta^{\prime}}+P-C^{\prime}(T)-\frac{\mu^{2} k W}{\eta^{\prime}(1+r)}\left(1-\frac{\delta h^{\prime}(\alpha \delta W)}{h(\alpha \delta W)}\right)=0
$$

Thus, the effect of rational expectations is to shift the firm's supply function to the left if there are labour market frictions. The firm gains from restricting the amount of training in order to raise the trainees' expectation of the wage and induce them to pay a higher price. 
However this additional term is always dominated by the incentive to increase training in order to increase the supply of skilled labour (the first term in (27)). Moreover, the additional effect is small if there are credit constraints or uncertainty, because trainees are then more reluctant to pay a higher price.

It is straightforward to show that, compared with the non-RE case, total training in equilibrium is lower. The equilibrium number of firms may rise, however: firms gain from their ability to push up the price of training. It can also be shown that the comparative statics results of section $2.5 \mathrm{do}$, in general, carry over to the rational expectations case. The main exception is that increasing the interest rate can, for some parameter values, increase training. A higher interest rate reduces the firm's ability to push up the training price, and can therefore have a positive effect.

\section{Policy}

Consider a policy maker who wishes to mitigate the effects on training of labour and capital market imperfections. Clearly, to achieve the first-best outcome, he must be fully informed about the causes of under-investment, and will need to employ a combination of different policy instruments to tackle different problems. But to identify the effects of various policies, we will examine their use in isolation. In this section, we use the model developed in section 2 to look first at the effects of regulating the training offered by firms, and then at what can be achieved using taxation to subsidise training. 


\subsection{Regulation of Firms' Training}

Suppose that the policy maker can regulate the training activity of firms, to determine the amount of training in each firm that chooses to enter the market for skilled labour. We will assume that he does not regulate skilled or trainee wages: these will be determined in the labour and training markets. His objective is to raise the welfare of firms and/or workers. From (22) and (23) we know that:

$$
\Psi_{f} \equiv \Psi_{f}(m) \text { and } \Psi_{w}=\Psi_{w}(m T)
$$

He chooses $T$ subject to:

$$
f(T)-W T+P T-C(T)=E(m) \quad \text { (entry condition for }
$$

firms)

and: $\quad W=\frac{f^{\prime}(T)}{1+\frac{1}{\eta}} \quad$ (the wage will be determined in the skilled labour market) and: $\quad W-\frac{\ln (h(\alpha \delta W))}{\alpha}-W_{0}=\phi(P, r) \quad$ (the price will be determined by demand ${ }^{5}$ ) The effect of his choice on welfare can be assessed from:

$$
\frac{d \Psi_{f}}{d T} \stackrel{\operatorname{sgn}}{=} \frac{d m}{d T} \text { and } \frac{d \Psi_{w}}{d T} \stackrel{\operatorname{sgn}}{=}\left(m+T \frac{d m}{d T}\right)
$$

(except in the case of a perfectly elastic supply of potential trainees $\left(W_{0}^{\prime}=0\right)$, when workers obtain no surplus and $\left.d \Psi_{w} / d T=0\right)$.

From the three conditions above we obtain:

$$
\frac{d m}{d T} \stackrel{\text { sgn }}{=} \frac{f^{\prime}(T)}{1+\eta^{\prime}}+P-C^{\prime}(T)+T\left(\frac{d P}{d T}-\frac{d W}{d T}\right)
$$

\footnotetext{
${ }^{5}$ Since the quantity of training is required to be the same in every firm, it does not matter whether trainees have rational expectations or form expectations as described in section 2.3.1.
} 
and

$$
\frac{d P}{d T}-\frac{d W}{d T}=\frac{-f^{\prime \prime}(T)}{1+\frac{1}{\eta^{\prime}}}\left(1-\frac{1}{1+r}\left(1-\delta \frac{h^{\prime}}{h}\right)\right)-\frac{m T}{1+r} W_{0}^{\prime}(m T)
$$

Consider the private rational expectations equilibrium, $\mathrm{T}^{\mathrm{RE}}$, in which the supply of training is determined by equation (27). At this level of training:

$\left.\frac{d m}{d T}\right|_{T=T^{R E}} \stackrel{\operatorname{sgn}}{=} \frac{(1-\mu) f^{\prime}\left(T^{R E}\right)}{1+\eta^{\prime}}+\frac{f^{\prime}\left(T^{R E}\right) \mu^{2} k}{\left(1+\eta^{\prime}\right)(1+r)}\left(1-\delta \frac{h^{\prime}}{h}\right)+T\left(\frac{d P}{d T}-\frac{d W}{d T}\right)$

The three terms in (31) represent three separate effects on firm welfare of raising training above the firms' private choice. The first two are unambiguously non-negative. The first term represents the gain, when there are labour market frictions, from internalising the benefits of training to other firms. The second term is the gain, when trainees have rational expectations, which comes from preventing firms from trying to raise their own training price by reducing training relative to other firms. This term is most significant when labour market frictions are high and capital market imperfections are low.

The third term represents the price effect - the effect on firm profits of the fall both in the skilled wage and in the price of training which accompany a rise in the number of trainees. From (30) we can see that this is non-negative in the special case of a perfectly elastic supply of trainees, and non-positive if there is a perfect capital market. Otherwise it is ambiguous. We examine these cases separately.

\section{Case1: Perfectly Elastic Supply of Trainees}

If all workers have the same reservation wage $\left(W_{0}^{\prime}=0\right)$ then their surplus is zero and social welfare is represented by $\Psi_{f}$. In this case the price effect (30) is non-negative, 
and if there are capital market imperfections it is strictly positive. Equation (31) therefore implies that firms will always gain from being required to increase training above the private equilibrium level, and this is true whether the source of under investment is labour market frictions, or credit constraints or uncertainty (or any combination). The policy maker's optimum choice $T_{p}$ is the maximand of firm welfare, which will be equal to the first-best (competitive) level $T_{f}$ if the capital market is perfect. Otherwise $T_{p}$ can be higher or lower than $T_{f}$, and welfare will necessarily be lower: this policy cannot prevent some dissipation of welfare in the imperfect capital market.

It is perhaps surprising that firms benefit from being required to pay for increased training when it is the trainees who are investing too little. The intuition for this result is as follows. With credit constraints and/or uncertainty about the skilled wage, the training demand function is flattened. Trainees are not prepared to pay a high price for training, but when the price is low many workers are willing to train without the need for further price reductions. Hence, firms can gain collectively from raising training because the improvement in the supply of skilled labour (the fall in the wage) outweighs the fall in the price of training along the demand function. Firms cannot act individually to increase training because they would lose trainees to other firms.

\section{Case 2: Perfect Capital Market; Upward Sloping Supply of Trainees}

When the only source of under-investment is labour market frictions, the policy maker can achieve the first-best (competitive) outcome. If he sets $T=T_{f}$, it can be seen from the three conditions above that the equilibrium number of firms will be $m_{f}$ ( that is, the same as the competitive solution (24)). Hence the welfare of both workers and firms 
will be the same as in the competitive outcome, although both the wage and the price will be lower.

Compared with the private equilibrium $T_{R E}$, the welfare of trainees will be higher if $W_{0}^{\prime}>0$. Firms will gain from being required to internalise the externality, but the price effect (30) is negative if $W_{0}^{\prime}>0$. In order to raise training, the welfare of workers has to be increased to attract more workers into the market, and this has a negative effect on profits. This is simply the standard monopsony effect: firms facing an upward-sloping supply of trainees would prefer, if they could act collectively, to restrict the quantity of training. Overall, therefore, the welfare of firms may be higher or lower at the competitive outcome $T_{f}$ than at the private equilibrium $T_{R E}$.

\section{Case3: The General Case}

With an upward-sloping supply of trainees $\left(W_{0}^{\prime}>0\right)$ changes in the level of training affect the welfare of trainees as well as firms, and the policy maker's optimal choice will depend on the relative weight he gives to the two groups. (As we saw in case 2 , even if he can achieve the first-best outcome, he might not choose to do so if he were mainly concerned about firm welfare).

In the general case, when $W_{0}^{\prime}>0$ and the capital market is imperfect, the price effect (30) on firm welfare is ambiguous. Capital market imperfections tend to make it positive, while if the supply of trainees is steeply sloping it will be negative. We can say, however, that capital market imperfections flatten training demand, and that if the training demand function is flatter than the skilled labour demand function (increased training reduces the skilled wage more than it raises the trainee wage) then firms will benefit from 
being required to increase training. Of course, even when the price effect is negative, they may benefit overall from counteracting the effects of labour market imperfections.

It follows immediately from (28) that if increasing training benefits firms, it also raises the welfare of workers. (The optimum level of training for workers is higher than the optimum for firms.)

Overall, if there is significant under-investment due to labour and/or capital market imperfections, then, a policy of requiring firms to finance an increase in training will produce a Pareto improvement, provided that the supply of trainees is not too steeply sloping. However, if the supply of trainees is inelastic, there may be a transfer of welfare from firms to workers. A cautious policy maker, not fully informed about labour and capital market effects on training and concerned to ensure that both workers and firms benefit, can do so by monitoring the effect of the policy on wages: he should ensure that the rise in trainee wages does not outweigh the fall in skilled wages.

Note that this conclusion depends crucially on the result that capital market imperfections flatten training demand. While this seems very plausible, particularly for credit constraints, it is not completely robust to changes in the specification of the way uncertainty effects the utility function. For the specification used here, the effect of uncertainty is that trainees discount higher wages more - the discount factor $h$ is increasing in the wage. If the discount factor were constant, increasing uncertainty would reduce demand without changing the slope of the demand function. Then there would be no corresponding price gain for firms from increasing training. 


\subsection{Taxation of Profits}

It is straightforward to see that the policy of regulation analysed in the previous section is exactly equivalent to a subsidy for training financed by a tax on firms' profits. The policy-maker can over-ride the firm's supply decision either directly, by regulating the quantity, or indirectly by manipulating the incentive to train.

\subsection{Wage Taxation}

A subsidy financed by taxation of skilled wages could, in principle, solve the problems caused by capital market imperfections. Releasing credit constraints is straightforward in this model: the policy maker could choose a proportional tax rate to implement the worker's optimal loan at a zero interest rate.

A proportional wage tax would also reduce the dispersion of wages between more and less efficient workers. Hence it would mitigate, but not eradicate, under-investment due to uncertainty. To go further, the tax would need to be progressive; and to achieve full income insurance the policy maker would need to set a marginal tax rate of $100 \%$ for more efficient workers, and hence equalise the income of more and less efficient workers.

This policy cannot have any effect on under-investment due to labour market imperfections. A subsidy financed by taxing skilled wages can be regarded as lowering the expected take-home wage below $W$ and lowering the consumer price of training below $P$, by the same amount, thus affecting the demand for training in (21) without changing the equations for supply. Thus the effect of the policy is simply to redistribute the worker's income between periods. With a perfect capital market, this can have no effect on the demand function either, since the worker can redistribute income costlessly himself by 
borrowing or saving. In general, the policy can achieve no more than to boost demand to the level that would occur with a perfect capital market. A tax and subsidy higher than that would simply induce workers to save.

\section{Training Levy Schemes}

It is often supposed that economic analysis tells us that levy schemes are an appropriate intervention only to the extent that there are training externalities between firms ${ }^{6}$. Moreover, since the consensus is that capital market imperfections are a more significant source of training market failure than the labour market imperfections which cause such externalities, there has been little support amongst economists for levy schemes.

The theoretical model developed in this paper allows for both sources of training market failure, and suggests several conclusions relevant to the debate on levy schemes. Firstly it demonstrates that there is a rationale for requiring firms to increase expenditure on training beyond their privately chosen level, either by regulating the quantity of training or by financing a subsidy through a tax on profits. This approach can achieve the first-best when market failure is due to labour market imperfections; more surprisingly, it can achieve a Pareto improvement when under-investment is caused by capital market imperfections. In the latter case, firms benefit from being required to subsidise training because, since all firms train more, the supply of skilled labour improves.

\footnotetext{
${ }^{6}$ See for example, Booth and Snower (1996b), Chapman (1993), Jones (1988) and (implicitly) Stevens (1996).
} 
It may be preferable to tackle capital market problems directly, by, for example, making loans available to trainees, or by a subsidy financed by a tax on skilled wages. But in practice, this approach may be difficult to implement. In particular, the moral hazard problems that are the source of capital market imperfections are not necessarily resolved by public intervention. Wage taxation providing full income insurance, for example, would have serious incentive problems. Furthermore, the policy maker may be uncertain about the relative significance of capital and labour market problems. In these circumstances, requiring firms to subsidise training may be a feasible second best.

So, if levy schemes provide a means of increasing the training expenditure of firms, they may be a useful policy tool. But in practice, the levy, or the firm's liability to spend on training, has been assessed (in the UK, France and other similar schemes) mainly as a proportion of the wage bill. This means that it acts not as a tax on profits, but as a tax on wages. Assuming that all employees benefit equally, each employee receives some subsidised training, financed by a proportional tax on his own wages spread over the whole period of employment. The theoretical model in this paper demonstrates (section 3.3) that this instrument can address the problem of credit constraints successfully, but cannot solve the poaching externality problem. Hence, if operated in this way, levy schemes should be regarded as a response to credit constraints. As such, they are entirely defensible; however, if it were possible to implement the levy in such a way that profits as well as wages were taxed, this would have the additional merits of ameliorating the effects of employers' labour market power, and individual uncertainty. 


\section{References}

Acemoglu, D. (1996) in A.L. Booth and D.J. Snower (eds.) Acquiring Skills, Cambridge University Press

Acemoglu, D. and J-S. Pischke (1998) "Why do firms train? Theory and Evidence", Quarterly Journal of Economics, 113(1), 79-120

Confederation of British Industry (1989) Towards a Skills Revolution, London

Confederation of British Industry (1997) The Meaning of Training, CBI Human Resources Brief, September

Becker, G. (1962) “Investment in Human Capital: A Theoretical Analysis”, Journal of Political Economy, 70 (5, part 2), 9-49

Bishop, J.H. (1991) “On-the-job training of new hires” in D. Stern and J.M.M. Ritzen (eds.) Market Failure in Training?, Berlin:Springer-Verlag.

Booth, A.L. and D.J. Snower (1996) Acquiring Skills, Cambridge University Press

Booth, A.L. and D.J. Snower (1996b) "Conclusions: government policy to promote the acquisition of skills" in Acquiring Skills, Cambridge University Press

Card, D. E. and A. B. Krueger (1995) Myth and Measurement: The New Economics of the Minimum Wage, Princeton University Press

Finegold, D.and Crouch, C. (1994) “A Comparison of National Institutions” in R. Layard, K. Mayhew and G. Owen (eds.) Britain's Training Deficit, Avebury.

Finegold, D. and D. Soskice (1988) “The Failure of Training in Britain: Analysis and Prescription", Oxford Review of Economic Policy, 4(3), 21-43 
Hamilton, J.H., (1987) “Optimal Wage and Income Taxation with Wage Uncertainty”, International Economic Review, 28(2), 373-88.

Jones, I. (1986) “Apprentice Training Costs in British Manufacturing Establishments: Some New Evidence", British Journal of Industrial Relations, 24(3), 333-62.

Jones, I. (1988) “An Evaluation of YTS”, Oxford Review of Economic Policy, 4(3).

Keep, E. and K. Mayhew (1996) "Evaluating the Assumptions that Underlie Training Policy" in A.L. Booth and D.J. Snower (eds.) Acquiring Skills, Cambridge University Press

Katz, E. and A. Ziderman (1990) "Investment in General Training: the Role of Information and Labour Mobility", Economic Journal, 100, pp. 1147-58

Layard, R. (1992) The Training Reform Act of 1994, Economic and Social Research Council, and London School of Economics and Political Science, Centre for Economic Performance.

Layard, R. , P. Robinson and H. Steedman (1995) “Lifelong Lear ning”, Occasional Paper No. 9, London School of Economics and Political Science, Centre for Economic Performance.

Lees, D. and Chiplin, B. (1970) "The Economics of Industrial Training”, Lloyds Bank Review, 96, 29-41

Malcolmson, J., J. Maw and B. McCormick (1997) “General Training by Firms, Contract Enforceability, and Public Policy", mimeo, University of Southampton Redding, S. (1996) “The Low-skill, Low-quality Trap: Strategic Complementarities between Human Capital and R\&D”, Economic Journal, 106, pp. 458-470 
Snower, D. J. (1996) “The Low-skill, Bad-job Trap” in A.L. Booth and D.J. Snower (eds.) Acquiring Skills, Cambridge University Press

Stevens, M. (1994) “A Theoretical Model of On-the-Job Training with Imperfect Competition" Oxford Economic Papers, 46, 537-62

Stevens, M. (1996) "Transferable Training and Poaching Externalities” in A.L. Booth and D.J. Snower (eds.) Acquiring Skills, Cambridge University Press

Stevens, M. (1999) "Human Capital Theory and UK Vocational Training Policy", Oxford Review of Economic Policy, 15(1).

Training Agency (1989) Training in Britain, London: HMSO

\section{Appendix}

\section{Derivation of result (8)}

We wish to calculate $a \equiv \frac{\partial W_{i}}{\partial T_{i}}$ at the symmetric equilibrium where $N_{i}=T_{i}=T$ and $W_{i}=\bar{W}_{i}=W$ for all $i$

Differentiatiating the first order conditions (6) with respect to $T_{i}$ gives (ignoring terms of order $1 / m)$ :

$$
\left(f^{\prime \prime}\left(N_{i}\right) \frac{\partial N_{i}}{\partial W_{i}}-1\right)\left[\frac{\partial N_{i}}{\partial T_{i}}+a \frac{\partial N_{i}}{\partial W_{i}}\right]-a \frac{\partial N_{i}}{\partial W_{i}}+\left(f^{\prime}\left(N_{i}\right)-W_{i}\right)\left[\frac{\partial}{\partial T_{i}}\left(\frac{\partial N_{i}}{\partial W_{i}}\right)+a \frac{\partial^{2} N_{i}}{\partial W_{i}^{2}}\right]=0
$$

From the expression for $N_{i}$ in (6) we obtain the required partial derivatives. Evaluating these at the symmetric equilibrium gives:

$$
\frac{\partial N_{i}}{\partial W_{i}}=\frac{\eta^{\prime} T}{W} ; \frac{\partial^{2} N_{i}}{\partial W_{i}^{2}}=\frac{T}{W^{2}}\left(\eta^{\prime}(\eta-1)-2 \eta^{2} \mu^{2}(1-\mu)\right) ; \frac{\partial N_{i}}{\partial T_{i}}=\mu ; \frac{\partial}{\partial T_{i}}\left(\frac{\partial N_{i}}{\partial W_{i}}\right)=\frac{\eta \mu(1-\mu)}{W}
$$


Hence:

$\left(f^{\prime \prime}(T) \frac{\eta^{\prime} T}{W}-1\right)\left[\mu+a \frac{\eta^{\prime} T}{W}\right]-a \frac{\eta^{\prime} T}{W}+\left(f^{\prime}(T)-W\right)\left[\frac{\eta \mu(1-\mu)}{W}+a \frac{T}{W^{2}}\left(\eta^{\prime}(\eta-1)-2 \eta^{2} \mu^{2}(1-\mu)\right)\right]=0$

But $f^{\prime}(T)=W\left(1+\frac{1}{\eta^{\prime}}\right)$ and, defining $|\varepsilon| \equiv \frac{-f^{\prime}(T)}{T f^{\prime \prime}(T)}$, we obtain, after a little more

manipulation:

$$
\frac{a T}{W}=-\frac{\mu}{\eta^{\prime}} \frac{\left(\frac{1+\eta^{\prime}}{|\varepsilon|}+\frac{\mu}{1+\mu}\right)}{\left(\frac{1+\eta^{\prime}}{|\varepsilon|}+\frac{1}{\eta^{\prime}}+1+\left(\frac{\mu}{1+\mu}\right)^{2}\right)}
$$

which leads directly to result (8).

\section{Comparative Statics for Capital Market Imperfections}

Consider the solution $T^{*}, m^{*}$ of equations (21).

Using the first two equations to eliminate $P$ and $W$, and differentiating the third and fourth equation with respect to $r$ gives:

$$
\begin{aligned}
& \frac{\partial T^{*}}{\partial r}\left[\frac{f^{\prime \prime}}{1+\frac{1}{\eta^{\prime}}}\left(\frac{\mu}{\eta^{\prime}}(1+r)+\left(1-\frac{\delta h^{\prime}}{h}\right)\right)-(1+r) C^{\prime \prime}-m W_{0}^{\prime}\right]-\frac{\partial m^{*}}{\partial r} T W_{0}^{\prime}=\phi_{r} \\
& \frac{\partial T^{*}}{\partial r}\left[\frac{f^{\prime}}{1+\eta^{\prime}}(1-\mu)+\left(C^{\prime \prime}-\mu \frac{f^{\prime \prime}}{1+\eta^{\prime}}\right) T\right]-\frac{\partial m^{*}}{\partial r} E^{\prime}=0
\end{aligned}
$$

Since all coefficients have unambiguous signs (note that $0<\delta<1$ and $0<h^{\prime}<h$ ) it follows directly that $\frac{\partial m^{*}}{\partial r}<0$ and $\frac{\partial T^{*}}{\partial r}<0$.

Similarly, differentiating with respect to $\delta$ :

$$
\frac{\partial T^{*}}{\partial \delta}\left[\frac{f^{\prime \prime}}{1+\frac{1}{\eta^{\prime}}}\left(\frac{\mu}{\eta^{\prime}}(1+r)+\left(1-\frac{\delta h^{\prime}}{h}\right)\right)-(1+r) C^{\prime \prime}-m W_{0}^{\prime}\right]-\frac{\partial m^{*}}{\partial \delta} T W_{0}^{\prime}=\frac{h^{\prime}}{h} \frac{f^{\prime}}{1+\frac{1}{\eta^{\prime}}}
$$


$\frac{\partial T^{*}}{\partial \delta}\left[\frac{f^{\prime}}{1+\eta^{\prime}}(1-\mu)+\left(C^{\prime \prime}-\mu \frac{f^{\prime \prime}}{1+\eta^{\prime}}\right) T\right]-\frac{\partial m^{*}}{\partial \delta} E^{\prime}=0$

leads to $\frac{\partial m^{*}}{\partial \delta}<0$ and $\frac{\partial T^{*}}{\partial \delta}<0$.

\section{Comparative Statics for Labour Market Imperfections}

As in 2. above, differentiate the third and fourth equations (21), now with respect to

$\kappa \equiv \frac{1}{\eta^{\prime}}$

$\frac{\partial T^{*}}{\partial \kappa}\left[\frac{f^{\prime \prime}}{1+\kappa}\left(\mu \kappa(1+r)+\left(1-\frac{\delta h^{\prime}}{h}\right)\right)-(1+r) C^{\prime \prime}-m W_{0}^{\prime}\right]-\frac{\partial m^{*}}{\partial \kappa} T W_{0}^{\prime}=\frac{f^{\prime}}{(1+\kappa)^{2}}\left(\left(1-\frac{\delta h^{\prime}}{h}\right)-\mu(1+r)\right)$

$\frac{\partial T^{*}}{\partial \kappa}\left[\frac{f^{\prime}}{1+\kappa} \kappa(1-\mu)+\left(C^{\prime \prime}-\mu \kappa \frac{f^{\prime \prime}}{1+\kappa}\right) T\right]-\frac{\partial m^{*}}{\partial \kappa} E^{\prime}=-(1-\mu) T \frac{f^{\prime}}{(1+\kappa)^{2}}$

The signs of the derivatives depend on the sign of $Z \equiv\left(1-\frac{\delta h^{\prime}}{h}\right)-\mu(1+r)$.

When $r$ and $\delta$ are zero, $Z=1-\mu$, and by solving for the two derivatives it can be verified

that $\frac{\partial T^{*}}{\partial \kappa}<0$ and $\frac{\partial\left(m^{*} T^{*}\right)}{\partial \kappa}<0$

When $r$ and/or $\delta$ is sufficiently large, $Z$ is negative. Again, solving for the derivatives gives

$$
\frac{\partial m^{*}}{\partial \kappa}>0 \text { and } \frac{\partial\left(m^{*} T^{*}\right)}{\partial \kappa}>0
$$

